borative activities with similar institutions and agencies world-wide:

(1) Environmental Resources, including energy efficiency and global trends, energy, environment and development, and world water resources;

(2) Environmental Technology, including clean production and low waste, energy technology, environmental technology transfer, and agricultural biotechnology;

(3) Environmental Impacts, including environmentally-sound management of low-grade fuels, climate change and sustainable development, and coordinated abatement strategies for acidic depositions;

(4) Environmental Policy and Management, including urban environmental problems, sustainable environments, and common-property management; and

(5) POLESTAR, a comprehensive modelling and scenario-based activity, investigating the dynamics of a foreseeable world with 10 thousand million people by the middle of the next century.

\section{Planning and Development Tools}

SEI has developed a number of planning and development tools to explore environment and development options globally, regionally, and nationally - particularly in developing countries. These include an energy assessment, planning, and accounting, system linked to an environmental database (LEAP), and a water evaluation and assessment planning tool (WEAP). LEAP has been used in more than 50 countries and WEAP is in use in relation to the problems of the Aral Sea and for water planning purposes in Rajastan, India.

In addition, SEI has developed a 'greenhouse' gas scenario system (G2S2). This gives current 'greenhouse' gas emission values by gas, sector, and all countries of the world. It is being used by OECD, UNEP, and individual developing countries (currently Nigeria).

SEI has also developed an acidic depositions model to help the coordination of abatement strategies (CASM). This model makes use of European country energy predictions, fuel sulphur, and nitrogen, contents together with features of combustion and conversion to estimate emissions. Atmospheric transfer coefficients are used to estimate deposition. Critical-load maps and cost curves for optimized abatement have been generated with CASM. Based on critical acidic loads and relative sensitivity classes, sensitivity mapping of terrestrial Asia has also been carried out with this system.

\section{SEI's Network}

SEI has chosen a global network approach rather than a more traditional institutional set-up. The work programme is carried out by a world-wide network of about 60 full- or part-time and affiliated staff and consultants, who are linked with the SEI Head Office in Stockholm or the SEI Offices in Boston (USA), York (UK), and Tallinn (Estonia). SEI has developed a large mailing register to communicate to key members of society in government, industry, university, NGOs, and the media around the world. For further information contact the undersigned:

ARNO RoSEMARIN, Information Manager
Stockholm Environmental Institute
Jäxntorget 84
Box 2142
10314 Stockholm
Sweden.
Tel. +4687230260
Telex 19580 SEI S
Fax: +4687230348
E-mail available at all offices.

\title{
Richard Spruce (1817-93), Botanist and Explorer
}

$\mathrm{T}$ he Linnean Society of London, England, UK, will be hosting a Commemorative Conference on the above during 20-22 September 1993 at the University of York, England, UK. Richard Spruce, one of the greatest of all Victorian naturalist-explorers, was born at Ganthorpe and died at Coneysthorpe, both on the Castle Howard estate, Yorkshire, England, UK. He spent 15 years of continuous botanical work in the Amazon valley and the Andes of Peru and Ecuador. The breadth of his interests, the detail and accuracy of his observations, and the meticulous recordings of all that he saw, were phenomenal.

Spruce's main studies ranged from bryophytes to trees, but little appears to have escaped his attention as he recorded the uses to which plants were put by the native tribes amongst whom he stayed, noted their customs and languages, sketched their villages, and mapped unexplored rivers. His major scientific works, Palmae Amazonicae and Hepatics of Amazon and Andes, were published in 1869 and 1884, respectively, and his journal was edited by A.R. Wallace and published in 1908 as Notes of a Botanist on the Amazon and Andes.

$A$ varied and interesting conference programme has been arranged, including a public lecture by Professor
Ghillian T. Prance (Director of Kew Gardens) and a reception at York Museum, a remembrance service at Terrington where Spruce is buried, visits to Spruce's home and Castle Howard, a conference dinner and lectures, posters and exhibits on Richard Spruce's contribution to botanical science, and on Botanical exploration of South America in general.

Accommodation has been arranged at the University of York for the period 19-22 September. Early regis-

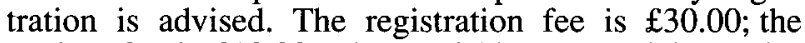
student fee is $£ 10.00$. Those wishing to participate (including presentation of a paper, poster, or exhibit) should apply for a registration form as soon as possible by contacting the undersigned:

MARK R.D. SEAWARD

Department of Environmental Science

University of Bradford, Bradford BD7 IDP

England, UK.

Tel: 0274-384212

Fax: 0274-384231 